\title{
NQ01 gene rs1800566 variant is not associated with risk for multiple sclerosis
}

\author{
José A G Agúndez ${ }^{1}$, Elena García-Martín², Carmen Martínez³ , Julián Benito-León ${ }^{4,5,6}$, Jorge Millán-Pascual , \\ Patricia Calleja ${ }^{5}$, María Díaz-Sánchez ${ }^{5}$, Diana Pisa ${ }^{8}$, Laura Turpín-Fenoll1, Hortensia Alonso-Navarro9 \\ Lucía Ayuso-Peralta $^{10}$, Dolores Torrecillas ${ }^{10}$, José Francisco Plaza-Nieto ${ }^{9}$ and Félix Javier Jiménez-Jiménez ${ }^{9,10^{*}}$
}

\begin{abstract}
Background: A possible role of oxidative stress in the pathogenesis of multiple sclerosis (MS) and in experimental autoimmune encephalomyelitis has been suggested. The detoxification enzyme NAD(P)H dehydrogenase, quinone 1 (NQO1) has been found up-regulated in MS lesions. A previous report described an association between the SNP rs1800566 in the NQO1 gene and the risk for MS in the Greek population. The aim of this study was to replicate a possible influence of the. SNP rs1800566 in the NQO1 gene in the risk for MS in the Spanish Caucasian population.

Methods: We analyzed allelic and genotypic frequency of NQO1 rs1800566 in 290 patients with MS and 310 healthy controls, using TaqMan Assays.

Results: NQO1 rs1800566 allelic and genotypic frequencies did not differ significantly between MS patients and controls, and were unrelated with age of onset of MS, gender, and clinical type of MS.
\end{abstract}

Conclusions: Our results indicate that NQO1 rs1800566 does not have an effect on MS disease risk.

Keywords: Multiple sclerosis, Genetics, Genetic polymorphisms, NQO1, Risk factors

\section{Background}

Multiple sclerosis (MS) is a chronic inflammatory demyelinating disorder with axonal degeneration of the central nervous system. Although the etiology of MS is not well understood, the interplay of both genetic and environmental factors is the most likely hypothesis [1-5]. With regard to the role of genetic factors, genome-wide association studies (GWAS) have confirmed more than 100 loci with genome-wide significance [6-8]. According to the most recent GWAS, approximately $22 \%$ of signals overlapped at least one other autoimmune disease signal [8], However, all loci except HLA showed modest oddsratio (OR) in the range of 1.1-1.3 [9]. In particular the association between MS and the HLA-DRB1*15:01 haplotype has been shown to be strong.

A number or reports have suggested a possible role of oxidative stress and lipid peroxidation in the inflammatory

\footnotetext{
* Correspondence: fjavier.jimenez@salud.madrid.org

${ }^{9}$ Section of Neurology, Hospital Universitario del Sureste, Arganda del Rey, Madrid, Spain

${ }^{10}$ Department of Medicine-Neurology, Hospital "Príncipe de Asturias", Universidad de Alcalá, Alcalá de Henares, Madrid, Spain

Full list of author information is available at the end of the article
}

processes and in the pathogenesis of MS [10-40]. Reactive oxygen species (ROS) generated in excess primarily by macrophages and microglia, have been implicated as mediators of demyelination and axonal damage [10]. The main results of studies on oxidative stress markers in the brain, spinal cord, and CSF, both in MS patients and in experimental autoimmune encephalomyelitis (EAE) are summarized in a table included as an Additional file 1: Table S1.

$\mathrm{NAD}(\mathrm{P}) \mathrm{H}$ dehydrogenase, quinone 1 (NQO1) is a phase II detoxification enzyme that catalyzes the one-electron reduction of endogenous and exogenous quinones, preventing their participation in redox cycling and subsequent generation of reactive oxygen species. This enzyme is encoded by the NQO1 gene (chromosome 16q22.1, Gene Identity 1728) (link http://www.ncbi.nlm.nih.gov/gene/1728). The enzymatic activity of NQO1 depends fundamentally on a single nucleotide polymorphism (SNP) at the NQO1 locus, rs1800566 (C609T), which produces a proline-toserine substitution at amino acid 187 (P187S) (link http://www. ncbinih.gov/pubmed/9000600). Individuals with rs1800566TT genotype completely lack NQO1 activity, whereas those 
with $\mathrm{rs} 1800566 \mathrm{C} / \mathrm{T}$ genotype present approximately threefold decreased enzyme activity [41].

Although NQO1 polymorphisms are not mentioned among the possible susceptibility genes in GWAS studies, the possible role of oxidative stress in the pathogenesis of MS makes it reasonable to analyse the possible relationship between NQO1 gene polymorphisms and the risk of MS. Moreover, NQO1 has been found to be markedly up-regulated in active demyelinating MS lesions $[13,14]$ Stavropoulou et al. [42], in a case-control association study involving $231 \mathrm{MS}$ patients and 380 controls, reported an association between the rs1800566CT and TT genotypes and the risk of developing MS, and a higher incidence of rs1800566CT genotype in patients with primary progressive MS. The aim of the present study was to replicate the findings by Stavropoulou et al. [42] in the Spanish population.

\section{Methods}

\section{Patients and controls}

We studied 290 unrelated Caucasian Spanish patients who fulfilled McDonald's criteria for definite MS [43], with no other previous neurological diseases. MS patients were recruited from the "Multiple Sclerosis Association of Madrid" ( $n=165$ cases), the Health Areas of the La-Mancha-Centro Hospital (Alcázar de San Juan, Ciudad Real, n = 65 cases), and University Hospitals "Doce de Octubre" (Madrid, $\mathrm{n}=30$ cases), and "Príncipe de Asturias" (Alcalá de Henares, Madrid, $n=30$ cases). Most of these patients had participated in previous studies of genetic association with MS risk [44-48]. The control group was composed of 310 healthy unrelated Caucasian Spanish individuals (students or professors from the University of Extremadura) gender and age-matched with the patients. Ethnicity and geographical origin for cases and controls was self-reported. All the participants were included in the study after giving written informed consent. Table 1 summarizes the characteristics of the individuals included in the study. The protocol was approved by the Ethics Committees of the University Hospitals "Príncipe de Asturias" and "Infanta Cristina" (Badajoz). The study was conducted according to the principles expressed in the declaration of Helsinki.

\section{Genotyping of rs1800566 polymorphism}

Genotyping for $r s 1800566$ was performed in genomic DNA obtained from venous blood samples of participants using TaqMan Assays (C__2091255_30, Life Technologies, Alcobendas, Madrid, Spain). Detection was carried out by qPCR in an Eppendorf realplex thermocycler. The amplification conditions were as follows: after a denaturation time of $10 \mathrm{~min}$ at $96^{\circ} \mathrm{C}, 45$ cycles of $92^{\circ} \mathrm{C} 15$ sec $60^{\circ} \mathrm{C} 90 \mathrm{sec}$ were carried out and fluorescence was measured at the end of each cycle and at endpoint. All samples were determined in triplicate and genotypes were assigned both by gene identification software (RealPlex 2.0, Eppendorf, Madrid, Spain) and by analysis of the reference cycle number for each fluorescence curve, calculated by the use of the CalQPlex algorithm (Eppendorf, Madrid, Spain).

\section{Statistical analysis}

Hardy-Weinberg equilibrium (HWE) both in MS patient and control groups was analyzed by the DeFinetti software (http://ihg.gsf.de/cgi-bin/hw/hwa1.pl). Allele and genotype frequency analysis was performed with SPSS ver. 17.

For categorical variables the intergroup comparison values were calculated using the chi-square or Fisher's exact tests when appropriate. For continuous variables, the Kolmogorov-Smirnoff test was used to analyze normality in the distribution. Then, the Student two sample $t$ test was used for variables that followed a normal distribution (age and age at onset); the Mann-Whitney test was used for the duration of disease and the severity scores expanded disability status scale and progression index, because no normal distribution was observed for this parameter. The association between the genotypes and the risk of developing MS was assessed by two-way contingency table analysis (http://statpages.org/ctab2x2. html). Statistical power was calculated for the sample size of this study (this was determined from allele frequencies with a genetic model analyzing the frequency for carriers of the disease gene with Odds ratio $(\mathrm{OR})=1.5, \mathrm{p}=0.05$ [49]). Two-tailed and one-tailed associations of the risk with the variant allele for ORs of $1.5 ; 1.4 ; 1.3 ; 1.2$; and 1.1 ; were, respectively: $84.6 \%$ and $90.9 \% ; 68.9 \%$ and $79.0 \%$; $47.4 \%$ and $59.8 \% ; 25.6 \%$ and $36.6 \%$; and $9.9 \%$ and $16.56 \%$.

Table 1 Characteristics of the individuals included in the study

\begin{tabular}{|c|c|c|c|c|c|}
\hline & Overall MS patients & RRMS & SPMS & PPMS & Control individuals \\
\hline Gender (females/males) & $200 / 90$ & $111 / 44$ & $59 / 33$ & $30 / 13$ & 213/97 \\
\hline Age (mean $\pm S D)$ & $43.8 \pm 11.3$ & $40.0 \pm 10.5$ & $47.2 \pm 9.9$ & $54.4 \pm 10.2$ & $43.7 \pm 12.2$ \\
\hline Age at onset (mean \pm SD) & $32.6 \pm 10.6$ & $29.5 \pm 8.5$ & $34.9 \pm 11.8$ & $43.4 \pm 11.6$ & - \\
\hline Disease duration (mean $\pm S D$ ) & $11.2 \pm 7.9$ & $10.5 \pm 8.2$ & $12.3 \pm 9.3$ & $11.0 \pm 7.7$ & - \\
\hline Expanded disability status scale (EDSS) (median, Interquartile range) & $3.0,4.50$ & $2.5,2.00$ & $6.5,0.90$ & $7.5,0.50$ & - \\
\hline Progression index (EDSS/MS duration) & $0.5 \pm 0.4$ & $0.3 \pm 0.2$ & $0.6 \pm 0.5$ & $0.7 \pm 0.4$ & - \\
\hline
\end{tabular}

RRMS Relapsing remitting Multiple Sclerosis. SPMS Secondary Progressive Multiple Sclerosis. PPMS Primary Progressive Multiple Sclerosis. 
Table 2 NQO1 rs1800566 genotype and allelic variants of patients with multiple sclerosis (MS) and healthy volunteers

\begin{tabular}{|c|c|c|c|c|c|c|c|c|c|}
\hline & $\begin{array}{l}\text { MS PATIENTS } \\
\text { N (\%, 95\% C.I.) }\end{array}$ & $\begin{array}{l}\text { CONTROLS N } \\
\text { (\%, 95\% C.I.) }\end{array}$ & $\begin{array}{l}\text { Intergroup } \\
\text { comparison values } \\
\text { OR }(\%, 95 \% \text { C.I.) P }\end{array}$ & $\begin{array}{l}\text { MS WOMEN } \\
\mathrm{N}(\%, 95 \% \text { C.I.) }\end{array}$ & $\begin{array}{l}\text { CONTROL } \\
\text { WOMEN N } \\
(\%, 95 \% \text { C.I.) }\end{array}$ & $\begin{array}{l}\text { Intergroup } \\
\text { comparison values } \\
\text { OR }(\%, 95 \% \text { C.I.) P }\end{array}$ & $\begin{array}{l}\text { MS MEN N } \\
(\%, 95 \% \text { C.I.) }\end{array}$ & $\begin{array}{l}\text { CONTROL MEN } \\
\text { (N (\%, 95\% C.I.) }\end{array}$ & $\begin{array}{l}\text { Intergroup } \\
\text { comparison values } \\
\text { OR }(95 \% \text { CI) P }\end{array}$ \\
\hline $\begin{array}{l}\text { rs1800566 } \\
\text { GENOTYPE C/C }\end{array}$ & $178(61.4,55.8-67.0)$ & $195(62.9,57.5-68.3)$ & Reference & $120(60.0,53.2-66.8)$ & $134(62.9,56.4-69.4)$ & Reference & $58(64.4,54.6-74.3)$ & $61(62.9,53.3-72.5)$ & Reference \\
\hline$C / T$ & $99(34.1,28.7-39.6)$ & $104(33.5,28.3-38.8)$ & $1.43(0.74-1.47), 0.810$ & $72(36.0,29.3-42.7)$ & $72(33.8,27.5-40.2)$ & $1.12(0.74-1.68), 0.597$ & $27(30.0,20.5-39.5)$ & $32(33.0,23.6-42.3)$ & $0.88(0.48-1.66), 0.708$ \\
\hline$T / T$ & $13(4.5,2.1-6.9)$ & $11(3.5,1.5-5.6)$ & $1.30(0.57-2.96), 0.540$ & $8(4.0,1.3-6.7)$ & $7(3.3,0.9-5.7)$ & $1.28(0.45-3.63), 0.646$ & $5(5.6,0.8-10.3)$ & $4(4.1,0.2-8.1)$ & $1.32(0.34-5.14), 0.693$ \\
\hline Total & 290 & 310 & & 200 & 213 & & 90 & 97 & \\
\hline Allele C & $455(78.4,75.1-81.8)$ & $494(79.7,76.5-82.8)$ & Reference & $312(78.0,73.9-82.1)$ & $340(79.8,76.0-83.6)$ & Reference & $143(79.4,73.5-85.3)$ & $154(79.4,73.7-85.1)$ & Reference \\
\hline Allele T & $125(21.6,18.2-24.9)$ & $126(20.3,17.2-23.5)$ & $1.08(0.82-1.42), 0.601$ & $88(22.0,17.9-26.1)$ & $86(20.2,16.4-24.0)$ & $1.12(0.80-1.56), 0.523$ & $37(20.6,14.7-26.5)$ & $40(20.6,14.9-26.3)$ & 1.00 (0.60-1.65), 0.988 \\
\hline Total alleles & 580 & 620 & & 400 & 426 & & 180 & 194 & \\
\hline
\end{tabular}

Major alleles and genotypes were assumed as reference values. P values correspond to logistic regression analyses. 
Table 3 NQ01 rs1800566 genotype and allelic variants in patients with multiple sclerosis (MS), and relation with the clinical evolutive type of MS

\begin{tabular}{|c|c|c|c|c|c|}
\hline & $\begin{array}{l}\text { BOUT ONSET MS (RELAPSING REMITTING } \\
\text { PLUS SECONDARY PROGRESSIVE MS) N }\end{array}$ & $\begin{array}{l}\text { Intergroup comparison } \\
\text { values OR }(95 \% \mathrm{Cl}), \mathrm{P}\end{array}$ & $\begin{array}{l}\text { PRIMARY PROGRESSIVE } \\
\text { MS N (\%, } 95 \% \text { C.I.) }\end{array}$ & $\begin{array}{l}\text { Intergroup comparison } \\
\text { values OR }(95 \% \mathrm{Cl}), \mathrm{P}\end{array}$ & $\begin{array}{l}\text { CONTROLS N } \\
(\%, 95 \% \text { C.I.) }\end{array}$ \\
\hline rs1800566 GENOTYPE C/C & $153(61.9 ; 55.9-68.0)$ & Reference & $25(58.1,43.4-72.9)$ & Reference & $195(62.9,57.5-68.3)$ \\
\hline $\mathrm{C} / \mathrm{T}$ & $85(34.4 ; 28.5-40.3)$ & $1.04(0.72-1.51) ; 0.822$ & $14(32.6,18.6-46.6)$ & $1.05(0.52-2.11), 0.891$ & $104(33.5,28.3-38.8)$ \\
\hline $\mathrm{T} / \mathrm{T}$ & $9(3.6 ; 1.3-6.0)$ & $1.04(0.39-2.79) ; 0.928$ & $4(9.3,0.6-18.0)$ & $2.84(0.84-9.59), 0.081$ & $11(3.5,1.5-5.6)$ \\
\hline Total & 247 & & 43 & & 310 \\
\hline Allele C & $391(79.1 ; 75.6-82.7)$ & Reference & $64(74.4,65.2-83.6)$ & Reference & $494(79.7,76.5-82.8)$ \\
\hline Allele T & $103(20.9 ; 17.3-24.4)$ & $1.03(0.76-1.40) ; 0.829$ & $22(25.6,16.4-34.8)$ & $1.35(0.80-2.27), 0.262$ & $126(20.3,17.2-23.5)$ \\
\hline Total alleles & 494 & & 86 & & 620 \\
\hline
\end{tabular}

All subgroups were compared with control subjects. Major alleles and genotypes were assumed as reference values. P values correspond to logistic regression analyses. 


\section{Results}

The frequencies of NQO1 rs1800566 genotypes and allelic variants in patients diagnosed with MS did not differ from those of controls (Table 2). The genotype and allele frequencies in MS patients and healthy subjects were in Hardy-Weinberg's equilibrium. Mean age at onset of MS did not differ significantly between patients carrying NQO1 rs1800566 C/C (mean $\pm \mathrm{SD}=32.1 \pm 10.2$ years, reference), $\mathrm{C} / \mathrm{T}$ (mean $\pm \mathrm{SD}=33.5 \pm 11.6$ years, $\mathrm{p}=0.220$ ) and $\mathrm{T} / \mathrm{T}$ (mean $\pm \mathrm{SD}=32.4 \pm 12.0$ years, $\mathrm{p}=0.270$ ). Association between the rs1800566 variant and MS risk was not observed when analyzing gender separately (Table 2). The distribution of the NQO1 rs1800566 genotype and allelic frequencies did not differ between each MS clinical evolutive type and controls (Table 3 ) or in the severity scores: Expanded Disability Status Score or EDSS ( $\mathrm{p}=0.508$ and $\mathrm{p}=0.370$ for heterozygous and homozygous carriers of the minor allele, respectively, as compared with homozygous carriers of the major allele) or progression index $(p=0.872$ and $p=0.673$ for heterozygous and homozygous carriers of the minor allele, respectively, as compared with homozygous carriers of the major allele).

\section{Discussion}

In contrast with the findings in the study by Stavropoulou et al. [42], we did not find significant differences either in the frequencies of rs1800566 genotypes, or in the frequencies of the allelic variants of this polymorphism in patients with MS when compared with healthy controls. In addition, rs1800566 polymorphism was neither associated with age at onset of MS, nor with clinical type of MS. Patient sample size and statistical power are higher in our study than in the study by Stavropoulou et al. [42].

A possible reason for the discrepancies between the study by Stavropoulou et al. [42] and the present one is the fact that the genotype distribution in the control group of the Stavropoulou et al. [42] study was in Hardy-Weinberg's disequilibrium (Pearson's $\mathrm{p}=0.0086$ ). The Hardy-Weinberg's disequilibrium was attributable to the female control group of the study by Stavropoulou et al. [42]. Another putative difference is that in the study by Stavropoulou et al. [42] the genotyping analysis was carried out by using qPCR melting curves, whereas in our study TaqMan genotyping was used.

Several SNPs have been described within the NQO1 gene. It should be noted that most association studies on NQO1 focusing on the SNP analyzed in this study show a relatively high minor allele frequency (about 20\% for Caucasian populations according to 1000 genomes). The rs1800566 analyzed in this study is common in Caucasian individuals; in fact it occurs in all human populations, and is classified as a pathogenic allele related with altered susceptibility to benzene toxicity and response to chemotherapy (see http://browser.1000genomes.org/Homo_sapiens/Variation/Phenotype $\mathrm{db}=$ core $; \mathrm{r}=16: 69744645-$ 69745645; $=\mathrm{rs} 1800566 ; \mathrm{vdb}=$ variation; $\mathrm{vf}=1366399)$.

The present study has some limitations. First, the size of the analyzed cohorts may not be sufficient for strict conclusions about the role of NQO1in MS (though adequate to detect an OR as small as 1.5, a more modest association would not be detected). Secondly, because the cohort study included MS patients with different degrees of severity, it is not adequate for the investigation of the influence of NQO1 genotypes on disability or severity of MS. The ideal study for this purpose should be prospective, including the genotyping of patients with a recent diagnosis of MS and a re-examination of the same patient cohort after similar long-term follow-up periods to establish evolutive type).

\section{Conclusions}

Taking in account the limitations of the present study, the results suggest that, in contrast with the Stavropoulou et al. [42] report, NQO1 rs1800566 genotypes and allelic variants are not associated with the risk for MS in Caucasian Spanish people. The fact that this particular SNP showed lack of association with MS risk in the present study does not exclude the possibility that other SNPs in the NQO1 gene could be associated with a modification in the risk of this disease.

\section{Additional file}

Additional file 1: Table S1. Results of studies of oxidative stress markers in the brain, spinal cord, and CSF of MS patients and in experimental autoimmune encephalomyelitis (EAE).

Competing interest

The authors declare that they have no competing interests.

\section{Authors' contributions}

JAGA participated in the conception and design of the study, acquisition of data, analysis and interpretation of data, drafting of the manuscript, critical revision of the manuscript, administrative, technical, and material support, supervision, and obtaining funding. EGM participated in the conception and design of the study, acquisition of data, analysis and interpretation of data, drafting of the manuscript, critical revision of the manuscript, administrative, technical, and material support, supervision, and obtaining funding. CM participated in acquisition of data, analysis and interpretation of data, critical revision of the manuscript, administrative, technical, and material support.

$\mathrm{JBL}$ participated in acquisition of data, and critical revision of the manuscript. JMP participated in acquisition of data, and critical revision of the manuscript. PC participated in acquisition of data, and critical revision of the manuscript. MDS participated in acquisition of data, and critical revision of the manuscript. DP participated in acquisition of data, and critical revision of the manuscript. LTF participated in acquisition of data, and critical revision of the manuscript. HAN participated in acquisition of data, analysis and interpretation of data, critical revision of the manuscript, administrative, technical, and material support. LAP participated in acquisition of data, and critical revision of the manuscript. DT participated in acquisition of data, and critical revision of the manuscript. JFPN participated in acquisition of data, and critical revision of the manuscript. FJJJ participated in the conception and design of the study, acquisition of data, analysis and interpretation of data, drafting of the manuscript, critical revision of the manuscript, 
administrative, technical, and material support, and supervision. All authors read and approved the final manuscript

\section{Acknowledgements}

We are grateful to Prof. James McCue for assistance in language editing. This work was supported in part by Grants PI12/00241, PI12/00324 and RETICS RD12/0013/0002 from Fondo de Investigación Sanitaria, Instituto de Salud Carlos III, Spain, and GR10068 from Junta de Extremadura, Spain. Financed in part with FEDER funds from the European Union.

\begin{abstract}
Author details
'Department of Pharmacology, University of Extremadura, Cáceres, Spain. ${ }^{2}$ Department of Biochemistry and Molecular Biology, University of Extremadura, Cáceres, Spain. ${ }^{3}$ Department of Pharmacology, University of Extremadura, Badajoz, Spain. ${ }^{4}$ CIBERNED,Centro de Investigación Biomédica en Red de Enfermedades Neurodegenerativas, Instituto de Salud Carlos III, Madrid, Spain. ${ }^{5}$ Service of Neurology, Hospital Universitario Doce de Octubre, Madrid, Spain. ${ }^{6}$ Department of Medicine, University Complutense, Madrid, Spain. ${ }^{7}$ Section of Neurology, Hospital La Mancha-Centro, Alcázar de San Juan, Ciudad Real, Spain. ${ }^{8}$ Centro de Biología Molecular Severo Ochoa (CSIC-UAM), Facultad de Ciencias, Universidad Autónoma, Cantoblanco, Madrid 28049, Spain. ${ }^{9}$ Section of Neurology, Hospital Universitario del Sureste, Arganda del Rey, Madrid, Spain. ${ }^{10}$ Department of Medicine-Neurology, Hospital "Príncipe de Asturias", Universidad de Alcalá, Alcalá de Henares, Madrid, Spain.
\end{abstract}

Received: 12 February 2014 Accepted: 8 April 2014 Published: 23 April 2014

\section{References}

1. Giordano M, D'Alfonso S, Momigliano-Richiardi P: Genetics of multiple sclerosis: linkage and association studies. Am J Pharmacogenomics 2002, 2:37-58.

2. Dyment DA, Ebers GC, Sadovnick AD: Genetics of multiple sclerosis Lancet Neurol 2004, 3:104-110.

3. Ramagopalan SV, Deluca GC, Degenhardt A, Ebers GC: The genetics of clinical outcome in multiple sclerosis. J of Neuroimmunol 2008, 201-202:183-199.

4. Pugliatti M, Harbo HF, Holmøy T, Kampman MT, Myhr KM, Riise T, Wolfson C: Environmental risk factors in multiple sclerosis. Acta Neurol Scand 2008 Suppl 188:34-40.

5. Duque B, Sepulcre J, Bejarano B, Samaranch L, Pastor P, Villoslada P: Memory decline evolves independently of disease activity in MS. Mult Scler 2008, 4:947-953.

6. Sawcer S, Hellenthal G, Pirinen M, Spencer CC, Patsopoulos NA, Moutsianas L, Dilthey A, Su Z, Freeman C, Hunt SE, Edkins S, Gray E, Booth DR, Potter SC, Goris A, Band G, Oturai AB, Strange A, Saarela J, Bellenguez C, Fontaine B, Gillman M, Hemmer B, Gwilliam R, Zipp F, Jayakumar A, Martin R, Leslie S, Hawkins S, Giannoulatou E, et al: Genetic risk and a primary role for cell-mediated immune mechanisms in multiple sclerosis. Nature 2011, 476:214-219.

7. Patsopoulos NA, Bayer Pharma MS Genetics Working Group, Steering Committees of Studies Evaluating IFN $3-1 \mathrm{~b}$ and a CCR1-Antagonist, ANZgene Consortium, GeneMSA, International Multiple Sclerosis Genetics Consortium: Genome-wide meta-analysis identifies novel multiple sclerosis susceptibility loci. Ann Neurol 2011, 70:897-912.

8. International Multiple Sclerosis Genetics Consortium (IMSGC), Beecham AH, Patsopoulos NA, Xifara DK, Davis MF, Kemppinen A, Cotsapas C, Shah TS, Spencer C, Booth D, Goris A, Oturai A, Saarela J, Fontaine B, Hemmer B, Martin C, Zipp F, D'Alfonso S, Martinelli-Boneschi F, Taylor B, Harbo HF, Kockum I, Hillert J, Olsson T, Ban M, Oksenberg JR, Hintzen R, Barcellos LF, Wellcome Trust Case Control Consortium 2 (WTCCC2); International IBD Genetics Consortium (IIBDGC), Agliardi C, Alfredsson L, Alizadeh M, et al: Analysis of immune-related loci identifies 48 new susceptibility variants for multiple sclerosis. Nat Genet 2013, 45:1353-1360.

9. Gourraud PA, Harbo HF, Hauser SL, Baranzini SE: The genetics of multiple sclerosis: an up-to-date review. Immunol Rev 2012, 248:87-103.

10. LeVine SM: The role of reactive oxygen species in the pathogenesis of multiple sclerosis. Med Hypotheses 1992, 39:271-274.
11. Newcombe J, Li H, Cuzner ML: Low density lipoprotein uptake by macrophages in multiple sclerosis plaques: implications for pathogenesis. Neuropathol \& App/ Neurobiol 1994, 20:152-162.

12. Haider L, Fischer MT, Frischer JM, Bauer J, Höftberger R, Botond G, Esterbauer $\mathrm{H}$, Binder CJ, Witztum JL, Lassmann H: Oxidative damage in multiple sclerosis lesions. Brain 2011, 134:1914-1924.

13. van Horssen J, Schreibelt G, Bö L, Montagne L, Drukarch B, van Muiswinkel $\mathrm{FL}$, de Vries HE: NAD(P)H:quinone oxidoreductase 1 expression in multiple sclerosis lesions. Free Radic Biol Med 2006, 41:311-317.

14. van Horssen J, Schreibelt G, Drexhage J, Hazes T, Dijkstra CD, van der Valk P, de Vries HE: Severe oxidative damage in multiple sclerosis lesions coincides with enhanced antioxidant enzyme expression. Free Radic Biol Med 2008, 45:1729-1737.

15. Bizzozero OA, DeJesus G, Callahan K, Pastuszyn A: Elevated protein carbonylation in the brain white matter and gray matter of patients with multiple sclerosis. J Neurosci Res 2005, 81:687-695.

16. Zheng J, Bizzozero OA: Decreased activity of the $20 \mathrm{~S}$ proteasome in the brain white matter and gray matter of patients with multiple sclerosis. J Neurochem 2011, 117:143-153.

17. Langemann $H$, Kabiersch A, Newcombe J: Measurement of low molecularweight antioxidants uric acid tyrosine and tryptophan in plaques and white matter from patients with multiple sclerosis. Eur Neurol 1992, 32:248-252.

18. van Horssen J, Drexhage JA, Flor T, Gerritsen W, van der Valk P, de Vries HE: Nrf2 and DJ1 are consistently upregulated in inflammatory multiple sclerosis lesions. Free Radic Biol Med 2010, 49:1283-1289.

19. Wilhelmus MM, van der Pol SM, Jansen $Q$, Witte ME, van der Valk $P$, Rozemuller AJ, Drukarch B, de Vries HE, Van Horssen J: Association of Parkinson disease-related protein PINK1 with Alzheimer disease and multiple sclerosis brain lesions. Free Radic Biol Med 2011, 50:469-476.

20. McMahon JM, McQuaid S, Reynolds R, FitzGerald UF: Increased expression of ER stress- and hypoxia-associated molecules in grey matter lesions in multiple sclerosis. Mult Scler 2012, 18:1437-1447.

21. Fischer MT, Sharma R, Lim JL, Haider L, Frischer JM, Drexhage J, Mahad D, Bradl M, van Horssen J, Lassmann H: NADPH oxidase expression in active multiple sclerosis lesions in relation to oxidative tissue damage and mitochondrial injury. Brain 2012, 135:886-899.

22. Choi IY, Lee SP, Denney DR, Lynch SG: Lower levels of glutathione in the brains of secondary progressive multiple sclerosis patients measured by 1H magnetic resonance chemical shift imaging at 3 T. Mult Scler 2011, 17:289-296.

23. Zheng J, Bizzozero OA: Accumulation of protein carbonyls within cerebellar astrocytes in murine experimental autoimmune encephalomyelitis. J Neurosci Res 2010, 88:3376-3385.

24. Dasgupta A, Zheng J, Perrone-Bizzozero NI, Bizzozero OA: Increased carbonylation, protein aggregation and apoptosis in the spinal cord of mice with experimental autoimmune encephalomyelitis. ASN Neuro 2013, 5:e00111.

25. Li S, Vana AC, Ribeiro R, Zhang Y: Distinct role of nitric oxide and peroxynitrite in mediating oligodendrocyte toxicity in culture and in experimental autoimmune encephalomyelitis. Neuroscience 2011, 184:107-119.

26. Toshniwal PK, Zarling EJ: Evidence for increased lipid peroxidation in multiple sclerosis. Neurochem Res 1992, 17:205-207.

27. Calabrese V, Raffaele R, Cosentino E, Rizza V: Changes in cerebrospinal fluid levels of malondialdehyde and glutathione reductase activity in multiple sclerosis. Int J Clin Pharmacol Res 1994, 14:119-123.

28. Ghabaee M, Jabedari B, Al-E-Eshagh N, Ghaffarpour M, Asadi F: Serum and cerebrospinal fluid antioxidant activity and lipid peroxidation in Guillain-Barre syndrome and multiple sclerosis patients. Int J Neurosci 2010, 120:301-304.

29. Seven A, Aslan M, Incir S, Altıntaş A: Evaluation of oxidative and nitrosative stress in relapsing remitting multiple sclerosis: effect of corticosteroid therapy. Folia Neuropathol 2013, 51:58-64.

30. Greco A, Minghetti L, Puopolo M, Cannoni S, Romano S, Pozzilli C, Levi G: Cerebrospinal fluid isoprostanes are not related to inflammatory activity in relapsing-remitting multiple sclerosis. J Neurol Sci 2004, 224:23-27.

31. Mattsson N, Haghighi S, Andersen O, Yao Y, Rosengren L, Blennow K, Praticò D, Zetterberg H: Elevated cerebrospinal fluid F2-isoprostane levels indicating oxidative stress in healthy siblings of multiple sclerosis patients. Neurosci Lett 2007, 414:233-236. 
32. Sbardella E, Greco A, Stromillo ML, Prosperini L, Puopolo M, Cefaro LA, Pantano P, De Stefano N, Minghetti L, Pozzilli C: Isoprostanes in clinically isolated syndrome and early multiple sclerosis as biomarkers of tissue damage and predictors of clinical course. Mult Scler 2013, 19:411-417.

33. Pennisi G, Cornelius C, Cavallaro MM, Salinaro AT, Cambria MT, Pennisi M, Bella R, Milone P, Ventimiglia B, Migliore MR, Di Renzo L, De Lorenzo A, Calabrese $\mathrm{V}$ : Redox regulation of cellular stress response in multiple sclerosis. Biochem Pharmacol 2011, 82:1490-1499.

34. Gonzalo H, Brieva L, Tatzber F, Jové M, Cacabelos D, Cassanyé A, Lanau-Angulo L, Boada J, Serrano JC, González C, Hernández L, Peralta S, Pamplona R, Portero-Otin M: Lipidome analysis in multiple sclerosis reveals protein lipoxidative damage as a potential pathogenic mechanism. J Neurochem 2012, 123:622-634.

35. Kalousová M, Havrdová E, Mrázová K, Spacek P, Braun M, Uhrová J, Germanová A, Zima T: Advanced glycoxidation end products in patients with multiple sclerosis. Praque Med Rep 2005, 106:167-174.

36. Ljubisavljevic S, Stojanovic I, Vojinovic S, Stojanov D, Stojanovic S, Cvetkovic T, Savic D, Pavlovic D: The patients with clinically isolated syndrome and relapsing remitting multiple sclerosis show different levels of advanced protein oxidation products and total thiol content in plasma and CSF. Neurochem Int 2013, 62:988-997.

37. Jiménez-Jiménez FJ, de Bustos F, Molina JA, de Andrés C, Gasalla T, Ortí- Pareja M, Zurdo M, Porta J, Castellano-Millán F, Arenas J, Enríquez de Salamanca R: Cerebrospinal fluid levels of alpha-tocopherol in patients with multiple sclerosis. Neurosci Lett 1998, 249:65-67.

38. de Bustos F, Navarro JA, de Andrés C, Molina JA, Jiménez-Jiménez FJ, Ortí-Pareja M, Gasalla T, Tallón-Barranco A, Martínez-Salio A, Arenas J: Cerebrospinal fluid nitrate levels in patients with multiple sclerosis. Eur Neurol 1999, 41:44-47.

39. Amorini AM, Petzold A, Tavazzi B, Eikelenboom J, Keir G, Belli A, Giovannoni G, Di Pietro V, Polman C, D'Urso S, Vagnozzi R, Uitdehaag B, Lazzarino G: Increase of uric acid and purine compounds in biological fluids of multiple sclerosis patients. Clin Biochem 2009, 42:2001-2006.

40. Kastenbauer S, Kieseier BC, Becker BF: No evidence of Increased oxidative degradation of urate to allantoin in the CSF and serum of patients with multiple sclerosis. J Neurol 2005, 252:611-612.

41. Kuehl BL, Paterson JW, Peacock JW, Paterson C, Rauth AM: Presence of a heterozygous substitution and its relationship to DT-diaphorase activity. Br J Cancer 1995, 72:555-561.

42. Stavropoulou C, Zachaki S, Alexoudi A, Chatzi I, Georgakakos VN, Terzoudi Gl, Pantelias GE, Karageorgiou CE, Sambani C: The C609T inborn polymorphism in $\mathrm{NAD}(\mathrm{P}) \mathrm{H}$ :quinone oxidoreductase 1 is associated with susceptibility to multiple sclerosis and affects the risk of development of the primary progressive form of the disease. Free Radic Biol Med 2011, 51:713-718.

43. McDonald WI, Compston A, Edan G, Goodkin D, Hartung HP, Lublin FD, McFarland HF, Paty DW, Polman CH, Reingold SC, Sandberg-Wollheim M, Sibley W, Thompson A, van den Noort S, Weinshenker BY, Wolinsky JS: Recommended diagnostic criteria for multiple sclerosis: guidelines from the International Panel on the diagnosis of multiple sclerosis. Ann Neurol 2001, 50:121-127.

44. Martínez C, García-Martín E, Benito-León J, Calleja P, Díaz-Sánchez M, Pisa D, Alonso-Navarro H, Ayuso-Peralta L, Torrecillas D, Agúndez JA, Jiménez-Jiménez FJ: Paraoxonase 1 polymorphisms are not related with the risk for multiple sclerosis. Neuromolecular Med 2010, 12:217-223.

45. García-Martín E, Martínez C, Benito-León J, Calleja P, Díaz-Sánchez M, Pisa D, Alonso-Navarro H, Ayuso-Peralta L, Torrecillas D, Agúndez JA, Jiménez-Jiménez FJ: Histamine-N-methyl transferase polymorphism and risk for multiple sclerosis. European Jouirnal of Neurol 2010, 17:335-338.

46. García-Martín E, Lorenzo-Betancor O, Martínez C, Pastor P, Benito-León J, Millán-Pascual J, Calleja P, Díaz-Sánchez M, Pisa D, Turpín-Fenoll L, AlonsoNavarro H, Ayuso-Peralta L, Torrecillas D, Lorenzo E, Plaza-Nieto JF, Agúndez JA, Jiménez-Jiménez FJ: LINGO1 rs9652490 and rs1 1856808 polymorphisms are not associated with risk for multiple sclerosis. BioMed Central Neurol 2013, 13:34.

47. García-Martín E, Agúndez JA, Martínez C, Benito-León J, Millán-Pascual J, Calleja P, Díaz-Sánchez M, Pisa D, Turpín-Fenoll L, Alonso-Navarro H, Ayuso-Peralta L, Torrecillas D, Plaza-Nieto JF, Jiménez-Jiménez FJ: Vitamin D3 receptor (VDR) gene rs2228570 (Fok1) and rs731236 (Taq1) variants are not associated with the risk for multiple sclerosis: results of a new study and a meta-analysis. Public Library of Sci One 2013, 8:e65487.
48. Agúndez JAG, Garcia-Martin E, Martínez C, Benito-León J, Millán-Pascual J, Calleja P, Díaz-Sánchez M, Pisa D, Turpín-Fenoll L, Alonso-Navarro H, Ayuso-Peralta L, Torrecillas D, Plaza-Nieto JF, Jiménez-Jiménez FJ: MAPT gene rs1052553 polymorphism is not associated with the risk for multiple sclerosis. Hum Immunol 2013, 74:1705-1708.

49. Pértegas Díaz S, Pita Fernández S: Cálculo del poder estadístico de un estudio. Cad de Atención Primaria 2003, 10:59-63.

doi:10.1186/1471-2377-14-87

Cite this article as: Agúndez et al:: NQO1 gene rs1800566 variant is not associated with risk for multiple sclerosis. BMC Neurology 2014 14:87.

\section{Submit your next manuscript to BioMed Central and take full advantage of:}

- Convenient online submission

- Thorough peer review

- No space constraints or color figure charges

- Immediate publication on acceptance

- Inclusion in PubMed, CAS, Scopus and Google Scholar

- Research which is freely available for redistribution 